\title{
Book Review Sustainable city regions: Space, place and governance
}

\author{
Tetsuo Kidokoro, Noboru Harata, Leksono Probo Subanu, Johann Jessen, Alain Motte and \\ Ethan Paul Seltzer (eds.) \\ cSUR-UT Series: Library for Sustainable Urban Regeneration, Vol. 7, Springer, Japan, 2008, hardcover, 334pp., \\ $£ 62.99$, ISBN: 978-4431781462
}

URBAN DESIGN International (2010) 15, 238. doi:10.1057/udi.2010.3

The need for urban regeneration has evolved as a result of the post war decline and the necessity to rebuild the housing and industries in Europe and some other parts of the world after the World War II. Since then, international and national government policies have been focused on the urban regeneration as one of the main strategies for the suppressing urban problems and facilitating development. This has expanded into urban regeneration programmes and initiatives that have been further influenced by Stockholm Conference on the Human Environment, the resolution of the United Nations on Environment and Development and the Agenda 21. As a consequence, a number of initiatives world-wide have been initiated to facilitate the sustainable development. In 2003, the Centre for Sustainable Urban Regeneration (cSUR) at the University of Tokyo, Japan, has been established to assist the creation of a new integrated knowledge for the sustainable urban regeneration. To present the achievements of coordinated international research and novel integrated approaches the centre has edited and published series of books on issues of sustainable urban regeneration.

Sustainable city regions: space, place and governance is a seventh volume of the cSUR coordinated book series 'Library for Sustainable Urban Regeneration'. It covers the urban regeneration and strategic spatial planning at the city-region level. So far, cities and towns have been developing as isolated entities. The geometrical increase in the urban population, with half of the world population already inhabiting the cities, and the constant expansion of urban areas have had developed into networks of cities unified by common regional location and close social and economic relationship. In the age of urbanisation, these city regions have come into the focus as a subject for the spatial urban development, in particular, the urban regeneration process. In this volume, the cSUR's research on sustainable urban regeneration of the city regions is reflected with an objective to establish the characteristics of global city regions and to provide possible strategies for the city regions governance. Main focus is drawn on the roles of regional cities as important focal points of city regions. The sustainable regeneration of regional cities, as creative regional nucleuses, is foreseen to be critical in their development as a whole, while the viable regional spatial strategies are essential for creating and strengthening the network of cities and towns.

The introduction of the book provides insights into the urban regeneration and the governance of city regions. The rest of the book is assembled from the empirical and comparative studies on city regions and their development in nine countries of Asia, Europe and North America. It includes a collection of case studies, which focus on urban regeneration, regional governance and sustainability. In conclusion, editors of the book offer a vision on the sustainable future of city regions and discuss integrated strategies for the sustainable urban regeneration in times of globalisation.

The book should be a useful resource for practitioners, researchers and those who are interested in the nature of emerging city regions and sustainable urban regeneration.

\author{
Naglis Malys \\ MCISB, University of \\ Manchester, Manchester, UK
}

